\title{
The use of information and computer technologies in the conditions of inclusive education
}

\author{
Elena Tyutryumova ${ }^{*}$ and Tatyana Pomytkina \\ Izhevsk State Medical Academy of the Ministry of Health of the Russian Federation, 426034, \\ Izhevsk, Russia
}

\begin{abstract}
In recent years, significant transformations have been taking place in the preschool education system, caused by changes in the scientific, methodological and material base of education and upbringing of children. One of the important conditions for updating is the use of new information technologies, primarily computer technologies. This allows, on the one hand, to increase the effectiveness of the educational process, on the other hand, to a greater extent to apply an individual approach in the process of teaching and upbringing of both normally developing children and children with various developmental disabilities, including speech.

The article examines the actual problem of realizing the pedagogical potential of using assistive technology devices, such as multimedia correction tools, in the inclusive education of preschool children with severe speech pathologies. The article analyzes domestic and foreign experience of using multimedia technologies in correctional practice. A study was carried out using various available multimedia tools for speech correction; both positive and negative aspects were identified. Based on the results obtained, the author's method was proposed in the form of a software and hardware complex with biofeedback, which can be effectively used in institutions implementing inclusive education.
\end{abstract}

\section{Eleventh section}

\subsection{Introduction}

In recent years, significant transformations have been taking place in the preschool education system, caused by changes in the scientific, methodological and material base of education and upbringing of children. A new requirement is the use of multimedia technologies in education. This allows, on the one hand, to increase the effectiveness of the educational process, on the other hand, to a greater extent to apply an individual approach in the process of teaching and upbringing of both normally developing children and children with various developmental disabilities, including speech.

\footnotetext{
* Corresponding author: elemerzlyakova@yandex.ru
} 
According to statistics, the number of children with speech disorders in recent years has a tendency to increase, therefore, at present; one of the urgent tasks of speech therapy is to increase the efficiency of the process of correcting speech disorders in preschool children. Modern correctional scientific schools are in search of means and forms of education for modern children, whose childhood and mental development is already different from previous generations. The optimal solution of this problem is facilitated by specialized computer technologies [1,2,3].

However, in studies directly related to children with speech disorders, the possibilities of speech correction by means of information and computer technologies have not been sufficiently studied. In particular, the influence of the use of educational computer programs on the correction of speech development has not been studied; the psychological and pedagogical conditions that contribute to the development of speech in older preschool children with speech disorders by means of information and computer technologies have not been determined. Despite the wide range of computer development programs and game manipulators (consoles, joysticks, simulation steering wheel and pedals, electronic balancing boards, etc.) on the market, not every one of them will be able to efficiently implement the correction process in eliminating speech disorders, in particular "Launching speech" with alalia.

In addition, the relevance of the study of multimedia technologies in the correction of speech pathology is due to the fact that children with disabilities in various nosological groups in most cases have severe speech disorders. At the same time, in the conditions of modern realities, where the whole world is immersed in the organization of inclusive education and actively discusses the success and failure in choosing the means of its implementation (Derrick Armstrong, Anne Sherrill Armstrong, Ilektra Spandagow, Mona Niemeyer, Svetlana Alekhina, Olga Ledyankina, etc.) [4-7], a complex of modern assistive technologies is needed, which could solve the issues of training, adaptation and correction of people with disabilities. In his writings, David Mitchell considers the possibility of introducing children with disabilities into educational institutions with healthy students. In his opinion, inclusive education must necessarily be accompanied by assistive technology devices, such as: special access technologies; adaptive technologies; available digital media; additional communication technologies; technologies for special education; training using computer technology.

David Mitchell [8] concluded, based on the results of meta-analysis studies, in comparing the classical form of education and training with the introduction of multimedia technologies in teaching children with disabilities. The effect size was 0.52 , which can be described as moderately positive. It was also found that students with speech and mental impairments responded best to multimedia technologies.

Thus, the purpose of our study was to study the technical characteristics, software and functionality of modern information and computer technologies used in the correction of speech dysfunctions in children, as well as to evaluate the effectiveness.

Tasks:

1. Research of technical characteristics, software and functionality of multimedia devices that will be used in corrective speech therapy activities.

2. Development of long-term planning of correction when using analog devices with preschool children with severe forms of speech impairment.

3. Investigation of the possibilities and disadvantages of the game corrective effect of analog devices in the formation of speech.

4. Development of the author's assistive technology for the correction of speech dysfunctions in children for the purpose of implementation in inclusive educational institutions. 


\section{Materials and methods}

In order to assess the effectiveness of the use of information and computer technologies, a correctional and developmental program for the development of speech was developed.

The experimental group included 30 children aged 2.5 to 5 years with the following speech therapy status:

- ZRR (delayed speech development);

- motor alalia (lack of speech);

- dysarthria of III and IV degrees of severity (the absence of speech or the speech of the child is incomprehensible even to close people).

To develop a correctional and developmental program, the following information and computer technologies were selected:

1. Multimedia software (author's presentations made in Microsoft Power Point, logorhythmic exercises in Widows Media).

2. Special training computer programs:

- "Speech Express" speech therapy portal "Mersibo";

- "Home speech therapist" (practical course).

3. Specialized speech therapy simulators and game manipulators:

- Dance mat "Stepmania" developed by the author's program of the MC "International Rehabilitation Clinic Kozyavkin" Lviv, Ukraine.

The correctional and developmental program was designed for 10 individual lessons with a frequency of 1-2 times a week, for 40 minutes.

The structure of each lesson includes the following speech therapy tasks:

1. Articulation and breathing exercises;

2. Onomatopoeia games;

3. Games for the development of phonemic perception;

4. Logorhythmic exercises for the development of the tempo-rhythmic side of speech;

5. Exercises to develop coordination and general motor skills.

To analyze the results, the method of mathematical statistics was used, to prove the shifts in values, the Wilcoxon test was used for related samples (T), due to the fact that in the sample of 30 cases, the data are not parametric.

\section{Results}

After the implementation of the correctional and developmental program for the launch of speech, the indicators of phonemic perception, onomatopoeia, tempo-rhythmic development and articulatory, fine and general motor skills increased. To prove the shifts in values, the Wilcoxon test was used for related samples (T), due to the fact that in the sample of 30 cases, the data are not parametric (Table 1, Fig.1).

Table 1. Shifts in values for the indicators phonemic perception, onomatopoeia, tempo-rhythmic development and articulatory, fine and general motor-skills.

\begin{tabular}{|c|c|c|c|c|c|c|}
\hline \multirow{2}{*}{ Indicator } & \multicolumn{2}{|c|}{ Mean } & \multicolumn{2}{c|}{ Middle rank } & \multicolumn{2}{c|}{ Validity of differences } \\
\cline { 2 - 7 } & Before & After & Before & After & T & $\mathrm{P}(<0.05)$ \\
\hline $\begin{array}{c}\text { Phonemic } \\
\text { perception }\end{array}$ & 1.3 & 1.9 & 0 & 3.5 & 2.449 & 0.014 \\
\hline $\begin{array}{c}\text { Articulating motor } \\
\text { skills }\end{array}$ & 1.1 & 1.6 & 0 & 3 & 2.236 & 0.025 \\
\hline Fine motor skills & 0.5 & 1.2 & 0 & 4 & 2.646 & 0.008 \\
\hline $\begin{array}{c}\text { General motor } \\
\text { skills }\end{array}$ & 0.8 & 1.8 & 0 & 5.5 & 3.162 & 0.002 \\
\hline
\end{tabular}




\begin{tabular}{|c|c|c|c|c|c|c|}
\hline Onomatopoeia & 0.5 & 1.8 & 0 & 5.5 & 2.919 & 0.004 \\
\hline $\begin{array}{c}\text { Tempo-phytmic } \\
\text { development }\end{array}$ & 0.1 & 0.5 & 0 & 2.5 & 2.000 & 0.056 \\
\hline
\end{tabular}

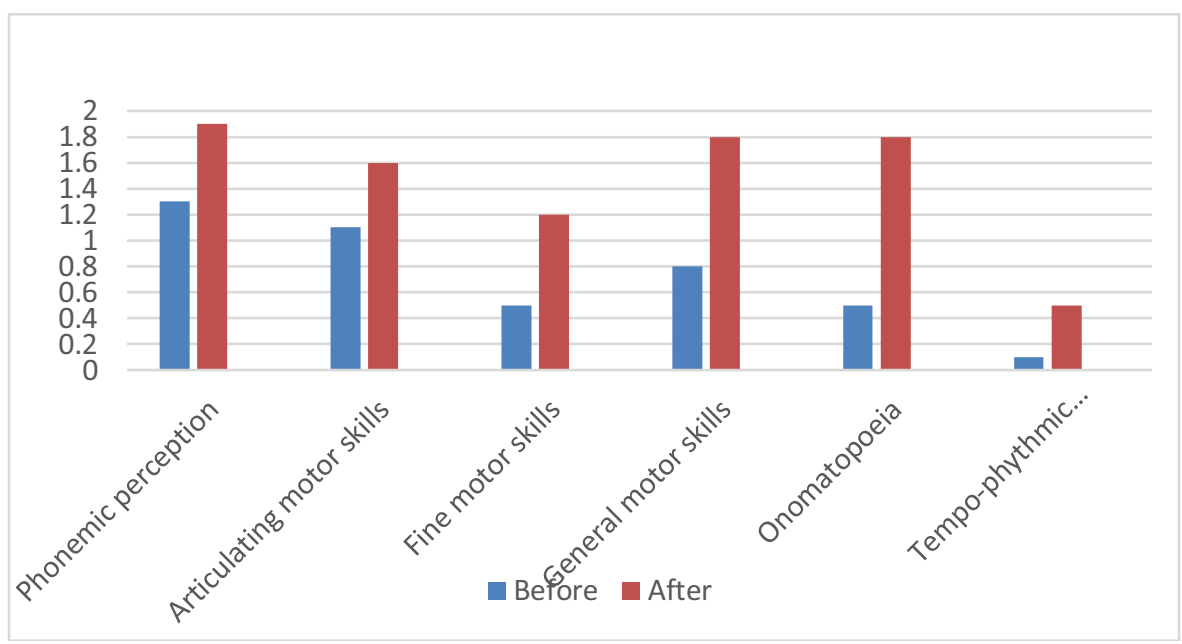

Fig. 1. Shifts in values in terms of phonemic perception, onomatopoeia, tempo-rhythmic development and articulatory, fine and general motor skills.

Thus, the selection of computer developmental programs and the use of the "Stepmania" dance mat in correction proves its effectiveness in speech therapy correction. It should be noted that the indicator of tempo-rhythmic development did not change dramatically in terms of "before" and "after", this is also manifested in the reliability of differences, which slightly exceeds $\mathrm{P}(<0.05)$. This is primarily due to the fact that all the children who participated in the experiment do not know phrasal speech, the development of which, in turn, directly depends on the tempo-rhythmic development [9]. The tempo-rhythmic organization of speech unites and coordinates all the components of oral speech, including lexical and grammatical structure formation, articulatoryrespiratory program and the whole complex of prosodic characteristics. Low values in the dynamics of this indicator may indicate that it is necessary to finalize and add games with musical instruments and exercises for motor planning to the developed correction program.

The maximum result after the experiment was achieved in the indicator of onomatopoeia (average value up to -0.5 ; after- 1.8 ), which is key in the process of starting speech. There is also a positive trend in the general indicators (cf. value up to -0.8 ; after1.8), small (cf. value up to -0.5; after-1.2), and articulation (cf. value before - 1.1; after 1.6) motor skills.

After the analysis of the literature review and the ascertaining experiment, the main advantages and disadvantages of using information and computer technologies in the correction of speech dysontogenesis were determined. In addition, as the experiment has shown, it is impossible to exclude traditional forms of speech therapy education from the informational correctional process. The results are shown in Table 2.

Table 2. Advantages and disadvantages of the game correctional influence of information and computer technologies in the formation of speech

\begin{tabular}{|l|l|}
\hline $\begin{array}{l}\text { Advantages of information and computer } \\
\text { technologies }\end{array}$ & $\begin{array}{l}\text { Disadvantages of information and } \\
\text { computer technologies }\end{array}$ \\
\hline The ability to maintain high motivation of & Limited duration of use with children. \\
\hline
\end{tabular}




\begin{tabular}{|c|c|}
\hline $\begin{array}{l}\text { the child throughout the entire correction } \\
\text { process. }\end{array}$ & $\begin{array}{l}\text { Sanitary and epidemiological station } \\
\text { requirements } 2.4 .1 .2660-10 \text {. } \\
12.21 \text {. Directly educational activities } \\
\text { using computers for children } 5-7 \text { years } \\
\text { old should be carried out no more than } \\
\text { one during the day and no more than } \\
\text { three times a week on the days of the } \\
\text { highest working capacity: on Tuesday, } \\
\text { Wednesday and Thursday. After } \\
\text { working with the computer, the } \\
\text { children are given gymnastics for the } \\
\text { eyes. The continuous duration of work } \\
\text { with a computer in the form of } \\
\text { educational games for children } 5 \text { years } \\
\text { old should not exceed } 10 \text { minutes and } \\
\text { for children } 6-7 \text { years old - } 15 \text { minutes. }\end{array}$ \\
\hline $\begin{array}{l}\text { Presentation of information on a } \\
\text { computer screen in a playful way arouses } \\
\text { in children a great interest in activities } \\
\text { with him. The child retains attention and } \\
\text { cognitive interest longer, in contrast to } \\
\text { traditional forms of speech therapy } \\
\text { classes. }\end{array}$ & $\begin{array}{l}\text { Due to the concomitant pathology of } \\
\text { the nervous system and temperamental } \\
\text { characteristics, this form of exercise } \\
\text { can motorically and emotionally } \\
\text { decelerate some children, while } \\
\text { oppressing (inhibiting) others. }\end{array}$ \\
\hline $\begin{array}{l}\text { A variety of exercises aimed at all aspects } \\
\text { of the child's speech development. }\end{array}$ & $\begin{array}{l}\text { Lack of universality of programs by } \\
\text { age, impairment, cognitive capabilities. } \\
\text { The need to combine and select their } \\
\text { own set of exercises and tasks for each } \\
\text { child. }\end{array}$ \\
\hline $\begin{array}{l}\text { Individualization of the correctional } \\
\text { process, the ability to choose the level of } \\
\text { difficulty for each child, taking into } \\
\text { account his psychophysiological abilities. }\end{array}$ & $\begin{array}{l}\text { The laborious pedagogical process of } \\
\text { preparation for the lesson (first of all, } \\
\text { the development of the author's Power } \\
\text { Point presentations). }\end{array}$ \\
\hline $\begin{array}{l}\text { Reducing the energy load of the teacher } \\
\text { himself, using such forms of training. }\end{array}$ & $\begin{array}{l}\text { Not all information and computer } \\
\text { systems are available for parents to } \\
\text { work out tasks at home (price, clear } \\
\text { interface, purchase, etc.). }\end{array}$ \\
\hline $\begin{array}{l}\text { Objective assessment of the child's } \\
\text { progress (saving the results in the } \\
\text { program itself). }\end{array}$ & $\begin{array}{l}\text { Inability to use by teachers with a low } \\
\text { level of ICT competence. }\end{array}$ \\
\hline $\begin{array}{l}\text { Saving space in the office, no need to } \\
\text { store paper didactic materials and } \\
\text { manuals (which, with repeated use, the } \\
\text { same child becomes uninteresting). It is } \\
\text { enough for the teacher to take a flashcard } \\
\text { or disk for class. }\end{array}$ & \\
\hline $\begin{array}{l}\text { Formation of volitional qualities and } \\
\text { perseverance in a child. } \\
\text { Assessment of your own success and } \\
\text { desire to finish the game, get emotional } \\
\text { reinforcement at the end (balls, fanfare, }\end{array}$ & \\
\hline
\end{tabular}




\begin{tabular}{|l|l|}
\hline etc. computer effects). & \\
\hline Corrective results are achieved faster in & \\
comparison with the traditional form of & \\
speech therapy.
\end{tabular}

Thus, the use of information and computer technologies in correctional classes has both advantages and disadvantages. This method has proven its effectiveness in speech therapy work when organizing an ascertaining experiment. When planning a lesson using a computer, the teacher needs to think over the goals and objectives, as well as the results that he is going to achieve together with the child. It is important to select gaming computer methods based on speech impairment, it is also important to know about contraindications for concomitant diseases of the child (for example, in case of epilepsy, flickering, flashing games with sharp loud sounds should be excluded).

\section{Discussion}

Thus, the analysis of domestic and foreign sources has shown the active introduction of multimedia technologies in the correctional and inclusive educational process. Computer technologies are effective as they can diversify a classic lesson with a speech therapist, they are visual, cause positive emotions in a child, and have a positive effect on the perception of educational material [10-11].

In modern educational practice, software and methodological complexes for preschool and primary general education are successfully used, in which educational material is presented in a fascinating animated form.

In teaching students with disabilities $(\mathrm{HH})$, special computer educational programs are used for each type of impairment, designed to form social and academic skills ("assistive technology"), including educational games. Australian scientists have drawn up requirements for the development of computer games for students with disabilities (the ability to repeat instructions for a child, the presence of quick positive feedback, automatic registration of responses, etc.). Each series of computer games is focused on training specific skills in children with a specific type of impairment. Scientists draw the attention of software developers to the need for close cooperation with specialists in the field of special education in order to create more computer programs and effective games, especially for preschool children [12-14].

At the same time, it is important to understand that computer technologies should not be used autonomously from the correctional process, otherwise they can turn into games of a leisure nature. Any software systems will be effective provided they are introduced into a classical correctional lesson, with a clear understanding of the goals and objectives that the teacher is going to achieve at the moment in the lesson.

In order to achieve maximum results by means of information and computer correction in speech therapy classes, a rug with sensor blocks was developed.

The methodological basis of this development is a neuropsychological approach to the systemic localization of higher mental functions (I. P. Pavlov and A. A. Ukhtomsky, L. S. Vygotsky, P. K. Anokhin, A. N. Leontiev and A. R. Luria) [15-19]. According to the proposed scientific approach, speech is not concentrated in any one part of the brain, but is a "dynamic" unit of several zones of the cerebral cortex. Figure 4 shows the posteriorfrontal, inferior-parietal, temporal, postero-temporal-inferior-parietal-anterior-occipital zones (TPO zone), which are responsible for the functioning of the human speech system. These departments are responsible for the operation of the analytic systems of these areas of the brain (motor-kinetic, kinesthetic, acoustic, spatial, visual analyzers), conducting afferent and efferent pathways related to the pyramidal and extrapyramidal 
systems, analyzers of sensitivity, hearing, vision, bulbar parts of the brain, visual , oculomotor, facial, auditory, glossopharyngeal, vagus and hypoglossal nerves. The state of the paranasal sinuses and the oral cavity, which play the role of resonator cavities, as well as the coordination of breathing and pronunciation of sounds are of great importance [20].

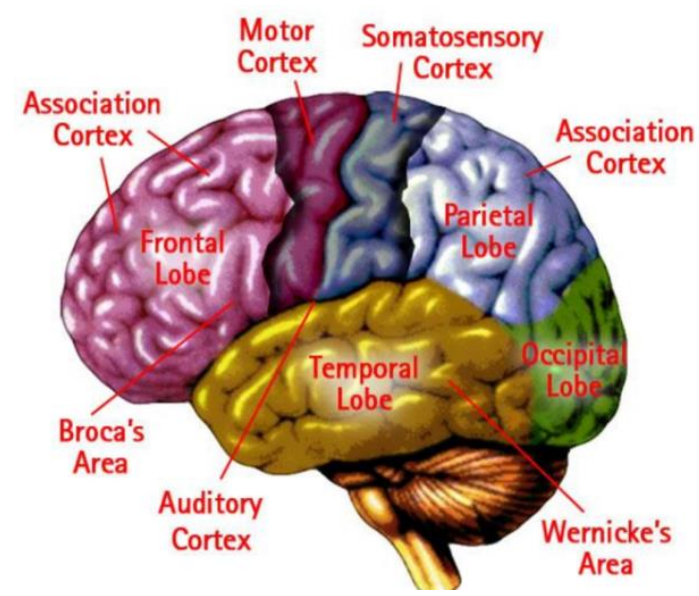

Fig. 4. Psychophysiological basis of speech. The parts of the brain involved in the formation of speech. Source: https://www.pinterest.ru/pin/369928556877154254/

The hardware and software complex for the correction of speech dysfunctions consists of a rectangular rug made of durable, non-slip material (neoprene, isolone, felt), equipped with sensor sensors that react to the contact of the rug surface with the child's foot. At this time, animation will be played on the monitor screen, imitating, for example, a child's walk in the forest or a boat trip along the river. A small microphone will be installed on the child himself, which will record his speech or breathing (depending on the correction task that the teacher will set himself) and these indicators will be transmitted to the computer screen and, depending on the child's correctness of the exercise, will be supported by animation in the form of a sun or a sad rainy cloud, as well as a sound signal .

The rug itself consists of 16 sectors, arranged in 2 rows of 8 pieces. The length of the mat is $217 \mathrm{~cm}$, width is $95 \mathrm{~cm}$. The power supply will be a USB bus, the cable length will be $3 \mathrm{~m}$. The software will be supplied on CD or DVD discs or on USB flash drives. External media (disk or USB drive) will be supplied with the program installer.

A rug with sensory blocks will be able to reduce the timing of speech "launch", maintain a positive emotional background and motivation of the child when attending classes with a speech therapist, reduce the workload of the specialist himself in the preparation and planning of correction measures (lesson notes, development of didactic materials, etc.) The key factor will be taking into account the age and psychophysiological characteristics of the child attending speech therapist, because in analog devices (computer games, dance mat) such indicators are not taken into account.

\section{Findings}

As a result of the study, an analysis of the game information and computer complexes available on the market was carried out, aimed at correcting higher mental functions in children with special educational needs.

In order to assess the effectiveness of the use of information and computer technologies, a group of preschool children with severe speech impairments was recruited. According to the results of the diagnosis, it was revealed that all children had an 
underdevelopment of auditory perception (phonemic hearing) - the children had difficulties in differentiating household noises, animal sounds. In addition, all children lacked the skill of onomatopoeia, most actively used only gestures and facial expressions in interpersonal communications. Underdevelopment of the motor sphere was noted - the subjects could not perform simple articulation exercises, finger gymnastics complexes, and were also motor awkward (uncertain, unsteady gait, frequent falls, inability to jump on two and one legs). Reproduction of simple rhythmic patterns (loud-quiet, fast-slow, etc.) was inaccessible to all children. On the basis of diagnostics for the children who participated in the experiment, a correctional and developmental program was developed to "start" speech using information and computer technologies. By the end of the study, the effectiveness of the inclusion of information and computer technologies in the traditional form of speech therapy lesson was proved. In $80 \%$ of children, positive dynamics in speech development was noted, the skill of onomatopoeia appeared, articulatory and fine motor skills improved, and a long cognitive interest remained in the course of the lesson.

At the same time, despite the positive results of the study, in the process of preparing for classes, difficulties were noted in the selection of correction methods, since most computer programs do not correspond to the capabilities of a child with gross developmental delays, including speech.

Taking into account the data obtained as a result of the study, a mat with sensor blocks was developed to correct speech dysfunction in preschool children. The sensor mat is aimed at "triggering" speech in non-speaking children by stimulating the areas of the brain involved in the formation of speech activity. This complex can be one of the most effective methods of correcting speech disorders in the conditions of inclusive education in kindergarten. In addition, work on this device is possible not only for children with speech pathology, but also for persons with intellectual disabilities, as well as lesions of the musculoskeletal system [21,22].

\section{References}

1. S.M. Adlof, T.P. Hogan, Language, Speech, and Hearing Services in Schools 49 (4), 762-773 (2018).

2. D.V.M. Bishop, M.J. Snowling, P.A. Thompson et al. Identifying language impairments in children. PLOS one 11 (7), 1-26 (2016).

3. B.G. Cook, S.L.Odom, Exceptional Children 79 (3), 135-144 (2013).

4. D. Armstrong, A.Ch. Armstrong, I. Spandagou, International Journal of Inclusive Education 15 (1), 29-39 (2011).

5. M. Niemeyer, The Irish Community Development Law Journal 3 (1), 49-64 (2014).

6. S.V. Alekhina, M.N. Alekseeva, E.L. Agafonova, Psychological Science and Education 1, 83 (2011).

7. O.V. Ledyankina, Social effects of medical education for persons with disabilities, Acmeology of vocational education: materials of the 13th All-Russian scientific and practical conference, March 17-18, 2016, Yekaterinburg, Russian state prof.pedagogical university - Yekaterinburg, 99-102.

8. D. Mitchell, What Really Works in Special and Inclusive Education Using evidencebased teaching strategies (Routledge, London-New York, 2008).

9. O.E. Gromova, Methodology for the formation of the initial children's vocabulary (TC Sphere, Moscow, 2003).

10. J.M. Fletcher, S. Vaughn, Child Development Perspectives 3 (1), 30-37 (2009). 
11. T. Halle, A. Metz, I. Martinez-Beck, Applying implementation science in early childhood programs and systems. Baltimore (MD: Paul H. Brookes Publishing Company, 2013)

12. S.I. Karpova, N.S. Murodkhodzhaeva, O.V. Tsaplina, A.P. Kaitov, TSPU Bulletin 6 (212), 46-56 (2020).

13. C. Eker, O. Karadeniz, International Journal of Humanities and Social Science 4 (14), 223-234 (2014).

14. K.C. Radley, W.R. Jenson, E. Clark, J.A. Hood, P.M. Nicholas, Intervention in School and Clinic 50 (1), 22-28 (2014).

15. P.K. Anokhin, Selected Works: Philosophical Aspects of the Theory of a Functional System (Nauka, Moscow, 1978).

16. L.S. Vygotsky, Development of higher mental functions (Publishing house of the Academy of Pedagogical Sciences of the RSFSR, Moscow, 1960).

17. A.R. Luria, Human brain and mental processes (Pedagogy, Moscow, 1970).

18. A.R. Luria, Fundamentals of neuropsychology. Textbook for students of higher educational institutions (Publishing Center "Academy", Moscow, 2002).

19. I.P. Pavlov, Selected works on the physiology of higher nervous activity (UCHPEDGIZ, Moscow, 1950).

20. https://www.defectologiya.pro/zhurnal/nejropsixologicheskie_osnovyi_razvitiya_rechi _rebenka/ (Date of appeal: 20.11.2020г.)

21. K.K. McGregor, L. Goffman, A. Van Horne et al., Perspectives of the ASHA Special Interest Groups 5 (1), 38-46 (2020).

22. S.M. Redmond, Journal of Speech, Language, and Hearing Research 59 (1), 133-142 (2016). 